\title{
PELATIHAN PENERAPAN PENGAJARAN REFLEKTIF DALAM PENGIMPLEMENTASIAN PENDEKATAN SCIENTIFIC APPROACH BAGI GURU BAHASA INGGRIS DI MAN MEDAN
}

\author{
Masitowarni Siregar ${ }^{1}$ Meisuri $^{2}$ Syamsul Bahri $^{3}$ \\ masitowarnisiregar@unimed.ac.id \\ Jurusan Bahasa dan Sastra Inggris, Fakultas Bahasa dan Seni, Universitas \\ Negeri Medan, Indonesia
}

\begin{abstract}
Abstrak.Pembelajaran aktif (active learning) adalah salah satu ciri utama yang dikehendaki oleh kurikulum 2013. Penelitian ini bertujuan untuk memberikan pelatihan penerapan Pengajaran Reflektif dalam pengimplementasian pendekatan Scientific Approach bagi guru Bahasa Inggris di MAN Medan. Madrasah Aliyah Negeri 1 (MAN 1) dan Madrasah Tsaniyah Negeri 2 (MTsN 2) Medan merupakan sekolah negeri yang berlokasi di Jl. Williem Iskandar No. 7 B, Kota Medan, Sumatera Utara. Sekolah ini juga termasuk sekolah yang aktif mengikuti berbagai kegiatan baik yang diselenggarakan oleh pihak pemerintah maupun lembaga lainnya. Namun, pada kenyatannya tidak semua siswa mampu melatih dirinya untuk berpikir kritis tanpa ada peran seorang guru yang terus berinovasi untuk mewujudkan suatu pembelajaran yang sesuai dengan tuntutan perubahan zaman. Penerapan Pengajaran Reflektif merupakan cara yang efektif dalam melatih siswa untuk terus berpikir kritis yang tentunya akan menjadi siswa yang aktif dan kreatif. Adapun target luaran yang akan dicapai adalah Publikasi ilmiah pada Jurnal ber ISSN/Prosiding jurnal Nasional; buku referensi/modul Pembelajaran Reflektif dalam pendekatan Scientific Approach; serta publikasi pada media masa cetak. Metode pelaksanaan yang dilakukan adalah model pelatihan penerapan Pengajaran Reflektif dalam pengimplementasian pendekatan Scientific Approach. Pelaksanaan kegiatan pembinaan ini dilakukan dengan empat tahapan yaitu 1) sosialisasi konsep dasar reflective teaching, 2) pelatihan reflective teaching dengan media power point, 3) tahapan pembimbingan reflective teaching, 4) tahap laporan draft buku tentang reflective. Pembinaan kemampuan reflective teaching para guru bahasa inggris yang dilakukan di sekolah mitra yaitu MAN 1 Medan dan MTSN 2 Medan sejauh ini telah dilaksanakan dengan baik dan diterima baik pula oleh sekolah mitra.
\end{abstract}

Kata Kunci: Pengajaran Reflektif, Scientific Approach, Guru, MAN

Abstract. Active learning is one of the main characteristics desired by the 2013 curriculum. This study aims to provide training on the application of Reflective Teaching in implementing the Scientific Approach approach for English teachers in MAN Medan. Madrasah Aliyah Negeri 1 (MAN 1) and Madrasah Tsaniyah Negeri 2 (MTsN 2) Medan are public schools located on Jl. Williem Iskandar No. 7 B, Medan City, North Sumatra. This school is also a school that actively participates in various activities both organized by the government and other institutions. However, in reality not all students are able to train themselves to think critically without the role of a teacher who continues to innovate to create learning that is in accordance with the demands of changing times. The application of Reflective Teaching is an effective way of training students to continue to think critically, which of course will become active and creative students. The output targets to be achieved are scientific publications in ISSN journals / National journal Proceedings; reference books / Reflective Learning modules in the Scientific Approach approach; as well as publications in the print media. The implementation method used is a training model for the application of Reflective Teaching in implementing the Scientific Approach approach. The implementation of this coaching activity is carried out in four stages, namely 1) socialization of the basic concepts of reflective teaching, 2) reflective teaching training using power point media, 3) reflective teaching guidance stages, 4) stage report draft book on reflective The development of reflective teaching skills for English teachers carried out in partner schools, namely MAN 1 Medan and MTSN 2 Medan, has so far been well implemented and well received by partner schools.

Keywords: Reflective Teaching, Scientific Approach, Teacher, MAN 


\section{MASITOWARNI SIREGAR ${ }^{1}$ MEISURI $^{2}$ SYAMSUL BAHRI $^{3}$ PELATIHAN PENERAPAN PENGAJARAN REFLEKTIF DALAM PENGIMPLEMENTASIAN PENDEKATAN SCIENTIFIC APPROACH BAGI GURU BAHASA INGGRIS DI MAN MEDAN}

\section{PENDAHULUAN}

Pendidikan merupakan suatu proses yang mencakup tiga dimensi, individu, masyarakat atau komunitas nasional dari individu tersebut, dan seluruh kandungan realitas, baik material maupun spiritual yang memainkan peranan dalam menentukan sifat, nasib, bentuk manusia maupun masyarakat (Nurkholis, 2013). Menurut Undang-Undang Republik Indonesia nomor 20 tahun 2003 pada pasal 1 ayat pendidikan adalah usaha sadar dan terencana untukmewujudkan suasana belajar dan proses pembelajaran agar peserta didik secara aktif mengembangkan potensi dirinya untuk memiliki kekuatan spiritual keagamaan, pengendalian dirinya, kepribadian, kecerdasan, akhlak mulia, serta keterampilan yang diperlukan dirinya, masyarakat bangsa, dan negara (Depdiknas, 2003). Dengan demikian dalam pelaksanaannya, terdapat dua unsur penting dalam pembelajaran yaitu model dan media pembelajaran yang keduanya saling berkaitan yang dapat meningkatkan kualitas pembelajaran (Arsyad dalam Erika, 2011). Komalasari (2003) menyatakan bahwa pembelajaran merupakan suatu sistem atau proses membelajarkan pembelajar yang direncanakan, dilaksanakan dan dievaluasi secara sistematis agar pembelajar dapat mencapai tujuan-tujuan pembelajaran secara efektif dan efesien.

Di abad ke 21, orang juga harus mampu berpikir kritis. Beers (tanpa tahun), mengemukakan adanya beberapa keterampilan yang perlu dimiliki untuk bisa hidup dengan baik di abad ke 21 . Keterampilan-keterampilan itu adalah: (1) creativity and innovation skill, (2) critical thinking and problem solving skill, (3) communication skill, (4) collaboration skill, (5) information management skill, (6)effective use of technology skill, (7) career and life skill, and (7) cultural awareness skill. Berdasarkan penjelasan tersebut, kemampuan berpikir kritis merupakan salah satu yang harus dimiliki oleh semua orang terutama para siswa. Oleh karena itu, penerapan kurikulum 2013 di sekolah merupakan salah satu cara dalam meningkatkan kemampuan siswa untuk menghadapi setiap tantangan yang dihadapi pada abad ke 21 tersebut.

Pembelajaran aktif (activelearning) adalah salah satu ciri utama yang dikehendaki oleh kurikulum 2013. Salah satu ciri keberhasilan dalam penerapannya adalah siswa banyak bertanya, dan giat mencari sendiri ilmu yang ingin dipelajarinya. Siswa tidak menunggu diberitahu oleh guru. Meskipun demikian, guru tidak boleh hanya diam tanpa memiliki inovasi untuk mengarahkan siswa menjadi siswa yang aktif dan selalu berpikir kritis.
Madrasah Aliyah Negeri 1 (MAN 1) dan Madrasah Aliyah Negeri 2 (MAN 2) Medan merupakan sekolah negeri yang terdapat di Medan, Sumatera Utara, beralamat di Jl. Williem Iskandar No. 7 B, Kota Medan, Sumatera Utara. Sekolah ini juga termasuk sekolah yang aktif mengikuti berbagai kegiatan baik yang diselenggarakan oleh pihak pemerintah maupun lembaga lainnya. Contohnya, MAN Medan merupakan sekolah yang selalu ikut berpartisipasi dalam kompetensi debat di Medan Sumatera Utara. Debat merupakan aktifitas yang menuntut suatu pemikiran kritis dalam menghadapi suatu permasalahan. Aktifitas tersebut sejalan dengan tujuan pemgimplementasian kurikulum 2013 yang menuntut siswa berperan aktif dan berpikir kritis. Hal ini tentunya selalu relevan dengan kegiatan pemerintah yang setiap tahunnya mengadakan perlombaan debat untuk siswa SMA/MA sederajat tingkat nasional, yaitu National Students Debating Championship (NSDC). Tujuan diadakannya kegiatan ini adalah untuk melatih siswa berpikir kritis dan meningkatkan kemampuan mereka dalam menghadapi setiap tantangan global kedepannya.

Pada kenyatannya tidak semua siswa mampu melatih dirinya untuk berpikir kritis tanpa ada peran seorang guru yang terus berinovasi untuk mewujudkan suatu pembelajaran yang sesuai dengan tuntutan perubahan zaman. Penerapan Pengajaran Reflektif merupakan cara yang efektif dalam melatih siswa untuk terus berpikir kritis yang tentunya akan menjadi siswa yang aktif dan kreatif. Reflektif yang dalam makna dasarnya adalah pengkajian terhadap diri sendiri yang telah dialami atau dilakukan selama ini sehingga terjadi kroscek antara apa yang dialami dengan apa yang dipelajari. Dengan demikian pembelajaran dalam konteks ini memberikan bandingan atau persamaan antara teori dengan kenyataan hidup yang dialami sehari-hari (Marnita, 2017). Namun, berdasarkan data yang diperoleh guru kurang melibatkan siswa dalam proses belajar mengajar, sehingga sebagian besar siswa tidak tuntas dalam belajarnya, kemampuan bertanya berhipotesis merancang percobaan meramalkan menerapkan konsep dan lain sebagainya sama sekali tidak dimiliki oleh siswa. Ada banyak hal yang menjadi penyebabnya, salah satunya adalah keterbatasan yang dimiliki guru terutama untuk memilih dan menerapkan model pembelajaran yang tepat serta sesuai dengan materi ajar merupakan salah satu faktor utama monotonnya proses belajar mengajar di dalam kelas. Menyikapi berbagai permasalahan tersebut, banyak solusi dapat diterapkan oleh guru, di antaranya 


\section{MASITOWARNI SIREGAR ${ }^{1}$ MEISURI $^{2}$ SYAMSUL BAHRI $^{3}$ PELATIHAN PENERAPAN PENGAJARAN REFLEKTIF DALAM PENGIMPLEMENTASIAN PENDEKATAN SCIENTIFIC APPROACH BAGI GURU BAHASA INGGRIS DI MAN MEDAN}

menggunakan model pembelajaran yang dapat menciptakan suasana yang menyenangkan dalam kelas dan siswa terlibat aktif di dalamnya. Pembelajaran yang peserta didiknya aktif akan dapat meningkatkan interaksi antar siswa dan taraf berfikir tingkat tinggi mahasiswa (Yerigan, 2008). Seperti yang telah dijelaskan di atas, pembelajaran reflektif merupakan model pembelajaran yang efektif untuk dilakukan oleh guru sehingga permasalahan-permasalahan yang dihadapi siswa dapat teratasi serta tujuan pembelajaran itu sendiri dapat tercapai.

Dari pembahasan diatas mengenai solusi yang akan diberikan untuk menyelesaikan permasalahan internal yaitu berbagai kegiatan pengabdian masyarakat dalam menyesaikan permasalahan melalui pelatihan penerapan Pengajaran Reflektif dalam pengimplementasian pendekatan Scientific Approach bagi Guru Bahasa Inggris di MAN Medan.

Dengan berbagai situasi yang di deskripsikan, dapat diuraikan berbagai permasalahan yang sedang dihadapi oleh guru di MAN Medan adalah kurangnya penerapan Pengajaran Reflektif dalam pengimplementasian pendekatan ScientificApproach di MAN Medan. Padahal model pembelajaran tersebut merupakan model yang efektif untuk mencapai tujuan pembelajaran yang sesuai dengan kurikulum 2013 sebagai bentuk penerapan kurikum 2013 itu sendiri. Hal ini disebabkan oleh beberapa faktor yaitu: pertama, guru di MAN Medan hanya menggunakan model pembelajaran konvensional dimana guru lebih cenderung aktif daripada siswa padahal dalam penerapan kurikul 2013, siswa harus aktif dan tentunya mampu berpikir kritis. Kedua, Guru belum pernah mendapatkan pelatihan Pembelajaran Reflektif dan mengimplemetasikan pembelajaran tersebut di kelas. Ketiga, banyak siswa yang tidak terlatih untuk berpikir kritis karena kurangnya motivasi pada saat terjadinya proses pembelajaran itu sendiri.

Dengan demikian, dapat disimpulkan bahwa guru berperan penting dalam mencapai tujuan pembelajaran serta peningkatan motivasi siswa untuk selalu aktif, kreatif, dan berpikir kritis. Maka, solusi yang ditawarkan adalah memastikan para guru mampu menerapkan Pengajaran Reflektifdalam pengimplementasian pendekatan Scientific Approach di MAN Medan. Untuk mencapai tujuan tersebut, maka perlu diadakannya suatu pelatihan dengan menghadirkan narasumber atau pelatih yang ahli bidangnya. Dengan demikian, tim pengusul dan mitra (MAN Medan) telah memiliki kesepakatan untuk mengatasi permasalahan yang terjadi. Kesepakatan tersebut adalah sebagai berikut.
1. PKM Pelatihan Penerapan Pengajaran Reflektif dalam Pengimplementasian Pendekatan Scientific Approach bagi Guru Bahasa Inggris di MAN Medan selama 6 bulan terhitung bulan Junis.d November 2020.

2. Selanjutnya, pihak MAN Medan menyediakan fasilitas ruangan yang nyaman untuk pengadaan pelatihan, diskusi dan pendampingan serta mengizinkan guru-guru Bahasa Inggris untuk mengikuti pelatihan, diskusi dan pendampingan perangkat pembelajaran Bahasa Inggris di waktu yang telah disepakati bersama.

3. Fasilitator pada pelatihan, diskusi dan pendampingan guru-guru merupakan tim dosen Bahasa Inggris Universitas Negeri Medan.

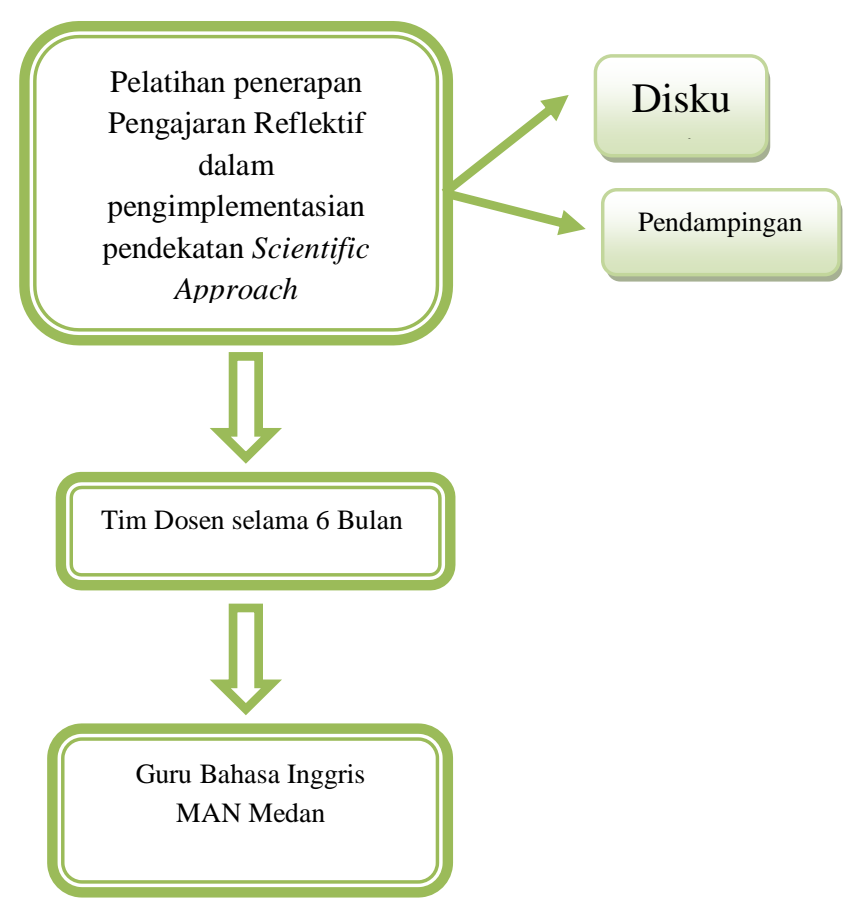

Gambar. 1 Model

\section{METODE PENELITIAN}

\subsection{Metode Pendekatan}

Metode pelaksanaan kegiatan pengabdian kepada masyrakat tentang: model pelatihan penerapan Pengajaran Reflektif dalam pengimplementasian pendekatan ScientificApproach bagi Guru Bahasa Inggris di MAN Medan selama 6 bulan terhitung bulan Juni s.d November 2020. 


\section{MASITOWARNI SIREGAR ${ }^{1}$ MEISURI $^{2}$ SYAMSUL BAHRI $^{3}$ PELATIHAN PENERAPAN PENGAJARAN REFLEKTIF DALAM PENGIMPLEMENTASIAN PENDEKATAN SCIENTIFIC APPROACH BAGI GURU BAHASA INGGRIS DI MAN MEDAN}

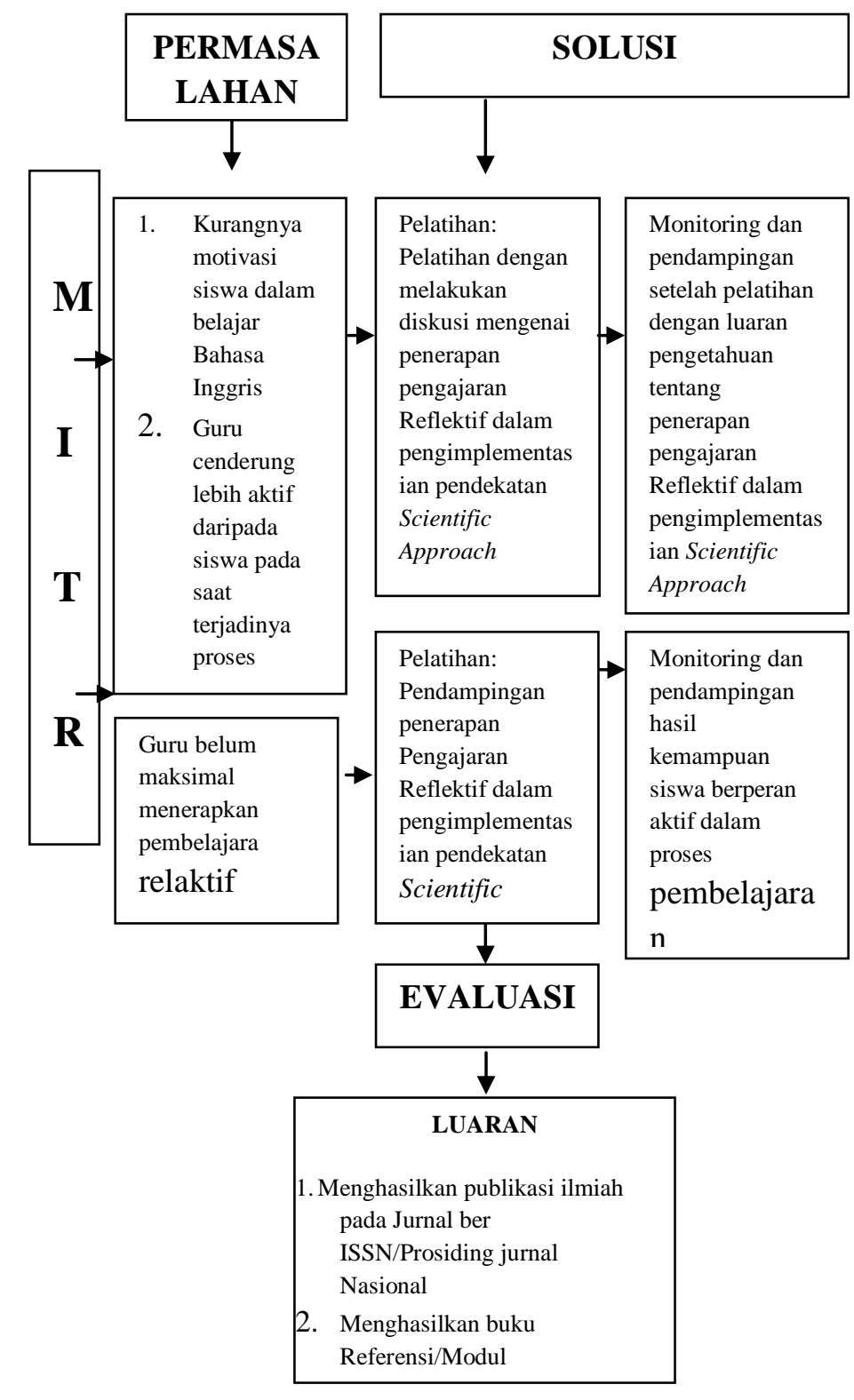

\subsection{Partisipasi Mitra Dalam Pelaksanaan Program}

Partisipasi mitra dalam pelaksanaan program adalah sebagai berikut.

1. Mitra berupaya dalam meningkatkan pengetahuan tentang Pengajaran Reflektif dalam Pengimplementasian Pendekatan Scientific Approach.

2. Mitra menyediakan fasilitas ruangan yang nyaman untuk pengadaan pelatihan, diskusi dan pendampingan selama 6 bulan.

3. Mitra mengizinkan guru-guru Bahasa Inggris untuk mengikuti pelatihan, diskusi dan pendampingan perangkat pembelajaran Bahasa Inggris di waktu yang telah disepakati bersama.

\subsection{Langkah Evaluasi Pelaksanaan Program \\ Langkah evaluasi pelaksanaan program dan keberlanjutan program di lapangan setelah kegiatan pengabdian kepada masyarakat selesai dilaksanakan adalah dengan mengadakan evaluasi penerapan}

pengajaran Reflektif dalam Pengimplementasian Pendekatan ScientificApproach bagi Guru Bahasa Inggris di MAN Medan. Selanjutnya diadakan evaluasi peningkatan kemampuan siswa dalam berperan aktif di kelas dan kegiatan lain di luar kelas.

\subsection{Prioritas Persoalan dan Jalan Keluar Pemecahan}

Penentuan prioritas persoalan berdasarkan kesepakatan tim pengusul dan mitra adalah guru berperan penting dalam mencapai tujuan pembelajaran serta peningkatan motivasi siswa untuk selalu akti, kreatif, dan berpikir kritis. Maka, solusi yang ditawarkan adalah memastikan para guru mampu menerapkan Pengajaran Reflektif dalam pengimplementasian pendekatan ScientificApproachdi MAN Medan. Untuk mencapai tujuan tersebut, maka perlu diadakannya suatu pelatihan dengan menghadirkan narasumber atau pelatih yang ahli bidangnya. Dengan demikian, tim pengusul dan mitra (MAN Medan) telah memiliki kesepakatan untuk mengatasi permasalahan yang terjadi. Kesepakatan tersebut adalah PKM Pelatihan Penerapan Pengajaran Reflektif dalam Pengimplementasian Pendekatan ScientificApproach bagi Guru Bahasa Inggris di MAN Medan selama 6 bulan terhitung bulan Juni s.d November 2020.

\section{HASIL DAN PEMBAHASAN}

Kegiatan pengabdian kepada masyarakat yang dilaksanakan di MAN 1 Medan dan MTSN 2 Medan melibatkan guru bahasa Inggris masing-masing sekolah tersebut tim pengabdi, dan mahasiswa Jurusan Bahasa dan Sastra Inggris.

\subsection{Peran Peserta}

Peserta berperan aktif dalam mengikuti kegiatan Pengabdian Kepada Masyarakat yang dilaksanakan di MAN 1 Medan dan MTSN 2 Medan, para guru antusias mengikuti kegiatan dari hari pertama sampai kepada hari terakhir, hal ini dapat dilihat dengan keaktifan bertanya para peserta dalam kegiatan tersebut.

\subsection{Model yang Diterapkan}

Kegiatan pengabdian masyarakat Pembinaan Kemampuan Reflective Teaching Guru di MAN 1 Medan dan MTSN 2 Medan dilakukan dengan tahapan sebagai berikut: 


\section{MASITOWARNI SIREGAR ${ }^{1}$ MEISURI $^{2}$ SYAMSUL BAHRI $^{3}$ PELATIHAN PENERAPAN PENGAJARAN REFLEKTIF DALAM PENGIMPLEMENTASIAN PENDEKATAN SCIENTIFIC APPROACH BAGI GURU BAHASA INGGRIS DI MAN MEDAN}

Tabel 1

Tahapan Kegiatan Pendampingan

\begin{tabular}{|c|c|c|c|c|}
\hline $\begin{array}{l}\mathbf{N} \\
\mathbf{0}\end{array}$ & $\begin{array}{c}\text { Taha } \\
\text { pan }\end{array}$ & & Kegiatan & $\begin{array}{c}\text { Partisipasi } \\
\text { Mitra }\end{array}$ \\
\hline 1 & $\begin{array}{l}\text { Persi } \\
\text { apan }\end{array}$ & b. & $\begin{array}{l}\text { Observasi } \\
\text { dan } \\
\text { wawancara } \\
\text { untuk } \\
\text { analisis } \\
\text { situasi } \\
\text { mengenai } \\
\text { Pembinaan } \\
\text { Kemampua } \\
\mathrm{n} \\
\text { Reflective } \\
\text { Teaching } \\
\text { Membangu } \\
\mathrm{n} \\
\text { komitmen } \\
\text { bersama } \\
\text { dengan } \\
\text { mitra. } \\
\text { Menentuka } \\
\mathrm{n} \text { jadwal } \\
\text { kegiatan, } \\
\text { dan, } \\
\text { Menyediak } \\
\text { an segala } \\
\text { keperluan } \\
\text { sarana dan } \\
\text { prasarana } \\
\text { dalam } \\
\text { mendukun } \\
\text { g } \\
\text { terlaksanan } \\
\text { ya kegiatan } \\
\text { pengabdian } \\
\text { dengan } \\
\text { baik. }\end{array}$ & $\begin{array}{l}\text { Menyiapkan } \\
\text { data yang } \\
\text { berhubungan } \\
\text { dengan } \\
\text { pembinaan } \\
\text { kemampuan } \\
\text { reflective } \\
\text { teaching. }\end{array}$ \\
\hline 2 & $\begin{array}{l}\text { Pelak } \\
\text { sanaa } \\
\mathrm{n}\end{array}$ & b. & $\begin{array}{l}\text { Sosialisasi } \\
\text { mengenai } \\
\text { konsep } \\
\text { dasar } \\
\text { tentang } \\
\text { reflective } \\
\text { teaching. } \\
\text { Pelatihan } \\
\text { teknik } \\
\text { mengajar } \\
\text { konsep } \\
\text { dasar } \\
\text { tentang } \\
\text { reflective } \\
\text { teaching } \\
\text { melalui } \\
\text { power } \\
\text { point } \\
\text { Pembimbin } \\
\text { gan } \\
\text { mengajar } \\
\text { konsep }\end{array}$ & $\begin{array}{l}\text { a. } \\
\text { Menyediakan } \\
\text { tempat } \\
\text { pelatihan } \\
\text { selama } \\
\text { kegiatan } \\
\text { berlangsung } \\
\text { b. Memotivasi } \\
\text { peserta agar } \\
\text { antusias } \\
\text { mengikuti } \\
\text { kegiatan }\end{array}$ \\
\hline
\end{tabular}

\begin{tabular}{|c|c|c|c|}
\hline & & \begin{tabular}{|l} 
dasar \\
tentang \\
reflective \\
teaching. \\
d. \\
Praktik \\
tentang \\
reflective \\
teaching.
\end{tabular} & \\
\hline 3 & $\begin{array}{l}\text { Eval } \\
\text { uasi } \\
\text { dan } \\
\text { Refle } \\
\text { ksi }\end{array}$ & 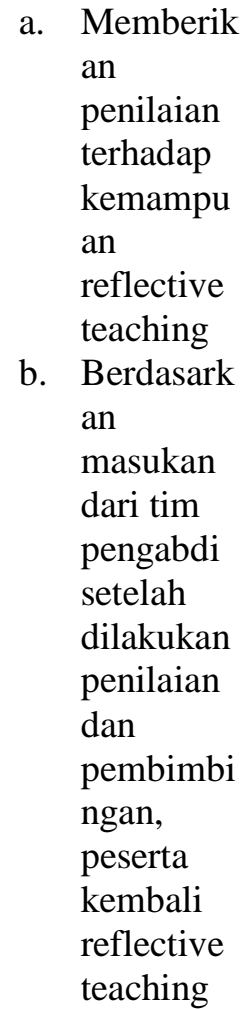 & $\begin{array}{l}\text { Membantu } \\
\text { peserta } \\
\text { melakukan } \\
\text { perbaikan- } \\
\text { perbaikan } \\
\text { dalam } \\
\text { reflective } \\
\text { teaching. }\end{array}$ \\
\hline 4 & $\begin{array}{l}\text { Tind } \\
\text { ak } \\
\text { Lanj } \\
\text { ut }\end{array}$ & $\begin{array}{l}\text { Semakin } \\
\text { terampilnya } \\
\text { peserta dalam } \\
\text { reflective } \\
\text { teaching }\end{array}$ & $\begin{array}{l}\text { Terus } \\
\text { berkomitmen } \\
\text { untuk } \\
\text { memotivasi } \\
\text { dan } \\
\text { membimbing } \\
\text { para guru } \\
\text { dalam } \\
\text { reflective } \\
\text { teaching. }\end{array}$ \\
\hline
\end{tabular}

\subsection{Pelaksanaan Kegiatan}

Kegiatan pengabdian ini bertujuan memberikan pelatihan pada para guru di MAN 1 Kota Medan dan MTSN 2 Medan untuk meningkatkan kemampuan reflective teaching mereka. Dimulai dengan pemaparan materi konsep dasar reflective teaching, termasuk di dalamnya teknik mengajarnya, kemudian dilanjutkan dengan Pelatihan teknik reflective teaching dengan cara melihat dari video atau power point, dan pembimbingan reflective teaching terhadap para guru sampai mampu memahami maksud atas reflective teaching tersebut secara mandiri sesuai dengan memasukkan unsur-unsur sehingga diperolehnya luaran yang diharapkan yaitu laporan berupa draft buku tentang reflective teaching. Pelaksanaan kegiatan pembinaan ini dilakukan mulai bulan Juli s.d Desember 2020 dengan empat tahapan yaitu sosialisasi konsep 


\section{MASITOWARNI SIREGAR ${ }^{1}$ MEISURI $^{2}$ SYAMSUL BAHRI $^{3}$ PELATIHAN PENERAPAN PENGAJARAN REFLEKTIF DALAM PENGIMPLEMENTASIAN PENDEKATAN SCIENTIFIC APPROACH BAGI GURU BAHASA INGGRIS DI MAN MEDAN}

dasar reflective teaching, pelatihan reflective teaching dengan media power point, tahapan pembimbingan reflective teaching, dan diakhiri dengan tahapan laporan draft buku tentang reflective, setelah dilakukannya pembinaan, rinciannya sebagai berikut.

1. Sosialisasi Pembinaan Reflective Teaching

Sosialisasi pembinaan kemampuan reflective teaching para guru di MAN 1 Medan dan MTSN 2 Medan dilakukan pada bulan Juli 2020. Dalam sosialisasi ini dilakukan pemaparan tujuan pembinaan kemampuan reflective teaching dan juga pemaparan materi yang berhubunga. Materi yang dipaparkan adalah: (1) pengertian reflective teaching, (2) fase reflective teaching, (3) elemen dalam reflective teaching dan (4) proses, alat dan bahan dalam relective teaching (Bartlett 1990). Dari kegiatan sosialisasi ini terlihat para guru bahasa inggris sangat antusias, hal ini terlihat dari keaktifan para guru dalam bertanya mengenai yang tidak mereka pahami.

2. Pelatihan Proses

dan

Pengembangan Reflective Teaching Setelah diberikan sosialisasi awal sebagai pengenalan pengabdian, maka tim pengabdi mengadakan dan memberikan materi tentang tahapan ataupun proses dari pengembangan reflective teaching tersebut untuk lebih mendalami tentang reflective teaching yang nantinya akan dituangkan oleh para guru dalam pengajarannya.

3. Pembimbingan Reflective Teaching Setelah mengadakan pelatihan dari proses reflective teaching, maka selanjutnya para guru dibimbing dalam mengaplikasikan reflective teaching. Tanya jawab tetap dilakukan sembari para guru mengaplikasikannya dari apa yang telah mereka kuasai sebelumnya. Dalam hal ini akan dilakukan penilaian terhadap reflective teaching guru tersebut.

4. Berlatih Menerapkan Reflective Teaching dan Prosesnya

Setelah tahap pembimbingan sudah dilakukan, para guru semuanya menunjukkan masing-masing kemampuannya dalam reflective teaching secara mandiri. Kemudian tulisan yang diperoleh nantinya akan disusun dalam draft buku tentang reflective teaching.

\subsection{Luaran dan Dampak Kegiatan}

Luaran dari kegitan pendampingan ini adalah draft buku ajar tentang reflective teaching untuk para guru di sekolah mitra. Ketika dilakukan pembinaan reflective teaching, para guru sudah mulai mampu mremahami tentang reflective teaching meskipun masih ditemukan kekurangan dalam memasukkan seluruh unsur yang terdapat dalam reflective teaching. Dari hasil yang didapatkan, dapat disimpulkan bahwa mereka atau para guru menyambut baik program pembinaan kemampuan reflective teaching yang diberikan dan berdampak positif. Hal ini juga tergambar saat pelatihan, dimana peserta sangat semangat dan antusias dalam menunjukkan keingintahuan mereka tentang reflective teaching. Selain itu, kelompok sasaran mengakui bahwa kegiatan ini membawa banyak manfaat untuk meningkatkan kemampuan dan keingintahuan guru tentang reflective teaching.

Kegiatan Pengabdian kepada Masyarakat Program Sekolah Binaan ini bertujuan untuk meningkatkan kemampuan reflective teaching para guru di sekolah mitra yaitu MAN 1 Medan dan MTSN 2 Medan. Penyelesaian masalah yang dihadapi oleh Mitra para guru bahsa inggris sekolah tersebut mampu memahami reflective teaching. Luaran yang dihasilkan dalam kegiatan Pengabdian kepada Masyarakat ini adalah Draft Buku yang berisikan tentang reflective teaching. Diharapkan kemampuan yang dimiliki setelah dilakukan pembinaan ini nantinya akan terus dilatih sehingga semakin berkembang.

Tabel 2

\begin{tabular}{|c|c|c|}
\hline \multicolumn{3}{|c|}{ Hasil dan Luaran yang Dicapai } \\
\hline No & $\begin{array}{c}\text { Hasil } \\
\text { Kegiatan }\end{array}$ & $\begin{array}{c}\text { Luaran yang } \\
\text { Dicapai }\end{array}$ \\
\hline 1 & $\begin{array}{l}\text { Para guru } \\
\text { bahasa inggris } \\
\text { sekolah mitra } \\
\text { mampu } \\
\text { memahami } \\
\text { tentang } \\
\text { reflective } \\
\text { teaching. }\end{array}$ & $\begin{array}{l}\text { Draft Buku } \\
\text { tentang reflective } \\
\text { teaching }\end{array}$ \\
\hline
\end{tabular}

Pelatihan reflective teaching dilanjutkan dengan memberi saran-saran terhadap latihan yang telah ditampilkan, para guru menumbuhkan minat yang besar untuk terus memahami tentang reflective teaching dengan Draft buku tentang reflective teaching. Sehingga, dengan kemampuan reflective teaching yang dimiliki, hal itu dapat mengawali minat para guru bahasa inggris sekolah mitra dan memotivasi mereka untuk mengembangkan kemampuan memahami reflective teaching. 


\section{MASITOWARNI SIREGAR ${ }^{1}$ MEISURI $^{2}$ SYAMSUL BAHRI $^{3}$ PELATIHAN PENERAPAN PENGAJARAN REFLEKTIF DALAM PENGIMPLEMENTASIAN PENDEKATAN SCIENTIFIC APPROACH BAGI GURU BAHASA INGGRIS DI MAN MEDAN}

\section{KESIMPULAN DAN SARAN \\ Kesimpulan}

Pembinaan kemampuan reflective teaching yang dilakukan di sekolah mitra yaitu MAN 1 Medan dan MTSN 2 Medan sejauh ini telah dilaksanakan dengan baik dan diterima baik pula oleh para guru dan sekolah mitra. Hal ini terlihat dari antuasias mereka dilakukan sosialisasi awal mengenai reflective teaching termasuk di dalamnya pemaparan mengenai konsep dasar reflective teaching hingga teknik dan proses dalam reflective teaching menulis puisi dan dilanjutkan dengan kegiatan pembimbingan reflective teaching hingga para guru mampu memahami reflective teaching secara mandiri, pelatihan reflective teaching dilanjutkan dengan memberi saran-saran terhadap latihan yang telah ditampilkan, para guru bahasa inggris sekolah mitra sudah benar-benar menumbuhkan minat yang besar untuk memahami reflective teaching yang ditunjukkan dengan Draft buku tentang reflective teaching. Sehingga, dengan kemampuan reflective teaching yang dimiliki, hal itu dapat mengawali minat para guru bahasa inggris sekolah mitra dan memotivasi mereka untuk mengembangkan kemampuan memahami reflective teaching.

\begin{abstract}
Saran
Kegiatan Pengabdian Kemitraan Masyarakat ini membantu meningkatkan kemampuan para guru bahasa inggris khususnya dalam kegiatan reflective teaching yang dapat mengawali minat mereka untuk mengembangkan kemampuan mengajar para guru tersebut. Untuk itu, diharapkan kemampuan yang dimiliki setelah dilakukan pembinaan ini nantinya akan terus dilatih sehingga semakin berkembang. Semakin mahir dalam memahami reflective teaching, hal itu yang nantinya dapat menunjukkan bahwa pengabdian ini berhasil membuat para guru sekolah mitra dalam memahami reflective teaching dan dalam mengajar disekolahnya menjadi meningkat dan lebih baik kedepannya.
\end{abstract}

\section{DAFTAR PUSTAKA}

Asari, A.R. 2014. Helping students experiencing mathematical thinking. Paper presented in International Workshop on Graph Masters and Seminar on Mathematics Education and Graph Theory. UNISMA: 7 - 9 Juni 2014
Komalasari, Kokom (2013). Pembelajaran Kontekstual: Konsep dan Aplikasi. Bandung: PT Refika Aditama

Marnita. 2012. Meningkatkan Keterampilan Proses Sains Siswa Melalui Penerapan Pakem Pada Konsep Perpindahan Kalor Di SMA. Jurnal Variasi Vol.2 No.1 hall6-21

Marnita. 2017. Model Pembelajaran Reflektif Learning untuk Meningkatkan Keterampilan Proses Sains dan Penguasaan Konsep Siswa Pokok Bahasan Kalor dan Perpindahannya di Kelas VII MTSN. Jurnal Pendidikan Al muslim. Vol.V. Hal. 23-29.

Nurkholis. 2013. Pendidikan Dalam Upaya Memajukan Teknologi. Jurnal Kependidikan. Vol. 1. Hal. 24-44.

Rahman, Abdur. 2014. Mengupayakan Pembelajaran Yang Sesuai Tuntutan Kurikulum 2013. https://www.researchgate.net/publicatio $\mathrm{n} / 273636240$.

Rais, Muhammad, dkk. 2019. Pembelajaran Relaktif Seni Berpikir Kritis, Analitis, dan Kreatif. Badan Penerbit UNM: Makassar.

Yerigan. 2008. Getting Active in The Classroom. Journal of College Teaching \& Learning, 5(6): 20-24 